\title{
REVIEW \\ Psychosocial issues in spinal cord injury: a review
}

\author{
MWM Post ${ }^{1,2}$ and CMC van Leeuwen ${ }^{1,2}$
}

\begin{abstract}
Study design: Review.
Objectives: To review literature on subjective well-being (SWB; mental health and life satisfaction) and on psychological and social support factors associated with these outcomes in people with spinal cord injury (SCI), in order to identify gaps in scientific knowledge and recommend research priorities.

Setting: Non applicable.

Methods: Narrative review of the SCl literature on life satisfaction and mental health (depression, anxiety, post-traumatic stress syndrome) outcomes in people with SCl. Further, reviews were performed of the SCI literature on psychological and social support variables associated with SWB and on psychosocial interventions aimed to improve SWB.

Results: People with $\mathrm{SCl}$ experience, on average, higher levels of distress and lower levels of life satisfaction compared with the general population. Individual differences, however, are large, and most people with $\mathrm{SCl}$ adapt well to their condition. A set of psychological and social support factors is strongly related to SWB. Intervention studies on cognitive behavioural therapy or coping effectiveness training to improve SWB show promising results, but suffer from methodological weaknesses (for example, lack of randomization and small sample size).

Conclusion: There is a need for cohort studies with sufficient sample size, which include people early after onset of SCl in order to enhance our understanding of the course of mental health and well-being after SCl. Cohort studies could also identify which people are at risk for long-term impairment of SWB. Finally, intervention studies on psychosocial interventions are needed to identify which interventions may improve SWB of people with SCI.
\end{abstract}

Spinal Cord (2012) 50, 382-389; doi:10.1038/sc.2011.182; published online 24 January 2012

Keywords: quality of life; psychological factors; spinal cord injuries; social support; adjustment disorders

\section{INTRODUCTION}

Because of improvements in medical care, the average life expectancy of people with spinal cord injury (SCI) has considerably increased in recent decades. ${ }^{1}$ However, SCI still is a major life event that leads to serious physical disability and secondary medical problems, which impact the quality of life (QoL) of the people involved. ${ }^{2,3} \mathrm{SCI}$ is associated with abnormal levels of psychological morbidity, ${ }^{4}$ substance abuse and risk of suicide. ${ }^{5}$ Consequently, psychosocial issues have become more prominent in SCI research in the last few decades.

QoL is a broad and ill-defined concept. ${ }^{6}$ QoL has been taken to be synonymous with health status, physical functioning, perceived health status, subjective health, health perceptions, symptoms, need satisfaction, individual cognition, functional disability, psychiatric disturbance, well-being and, often, several of these at the same time. ${ }^{7}$ Three broad approaches to the operationalization of QoL can be found in the literature: (1) by equating QoL with health, (2) by equating it with subjective well-being (SWB) and (3) by treating QoL as a superordinate construct. ${ }^{8}$ This paper is focused on SWB.

SWB is defined as how people evaluate their own lives. ${ }^{9}$ These evaluations can be more focal (for example, marital satisfaction or satisfaction with one's car) or broader (for example, general life satisfaction or satisfaction with the self). In addition, these evaluations can be cognitive-in terms of satisfaction judgments—or they can be affective (moods and emotions, which are reactions to what is happening in one's life). Moods and emotions are considered more variable over short periods than life satisfaction. ${ }^{9}$ Mental health, in this manuscript used as a general term covering mood, emotions and distress, and life satisfaction can be considered as two different, but related, SWB outcomes of SCI. Elsewhere we have shown that mental health influences well-being, but not the reverse. ${ }^{10}$ This is consistent with theory that SWB is a satisfaction judgment, including judgment of one's mood. ${ }^{9}$

Many rehabilitation clinicians and researchers have been surprised by the results of SWB studies in people with SCI, showing that SWB in this group is better than what is expected for such a serious injury. ${ }^{2,11}$ However, there are large individual differences, and a substantial group experiences persistent low SWB. ${ }^{12,13}$ These differences are not well predicted by the severity of the SCI (level and completeness) and resulting impairments, such as loss of bladder control, spasticity and pain. ${ }^{2,13-17}$ Psychosocial factors must be taken into account to explain differences in SWB.

The aims of this paper are: (1) to review the evidence on levels of SWB in people with SCI, (2) to review the evidence on associations between psychosocial (psychological and social) factors and SWB in people with SCI, (3) to review the evidence on interventions aimed at improving psychosocial functioning in people with SCI and (4) to identify gaps in the scientific understanding of SWB in people with SCI and to make research recommendations.

\footnotetext{
${ }^{1}$ Rudolf Magnus Institute of Neuroscience, University Medical Center Utrecht and Center of Excellence in Rehabilitation Medicine, De Hoogstraat, Utrecht, The Netherlands and 2Swiss Paraplegic Research, Nottwil, Switzerland

Correspondence: Dr MWM Post, Center of Excellence in Rehabilitation Medicine, De Hoogstraat, 3583 TM Utrecht, The Netherlands.

E-mail: m.post@dehoogstraat.nl
}

Received 26 July 2011; revised 14 November 2011; accepted 27 November 2011; published online 24 January 2012 


\section{METHODS}

Literature searches were performed in PubMed. For reasons of time and space, studies not addressing psychosocial predictors or SWB outcomes were excluded. In the searches, relevant terms for SWB outcomes were used, for example, life satisfaction, well being, mental health, anxiety, depression, posttraumatic stress syndrome, mood and QoL. Included were studies on SWB outcomes in people with traumatic or non-traumatic SCI, excluding the literature on participation, health-related QoL outcomes, secondary conditions (for example, chronic pain) and concomitant traumatic brain injury. Because of the presence of many papers on mental health, reporting of this was restricted to publications since 2000. The description of psychological factors is based on a recent systematic review covering 48 studies. ${ }^{18}$ Social support studies were collected from another recent review. ${ }^{19}$ As the focus of this paper is on psychosocial issues, papers on relationships between SWB and disablement factors, ${ }^{14}$ secondary condition, ${ }^{20}$ and environmental factors, ${ }^{21}$ except for social support, ${ }^{19,22}$ have been excluded, as well as papers on the importance of psychosocial factors as predictors of functional outcomes, ${ }^{23}$ pain $^{24}$ and other secondary conditions. ${ }^{25,26}$

\section{RESULTS}

\section{Life satisfaction of people with SCI}

Mean life satisfaction scores are instrument dependent and need a reference to reveal meaningful information. Several studies have compared life satisfaction of people with long-standing SCI with that of the general population (Figure 1). ${ }^{14,27-44}$ The differences between mean scores in people with SCI and in the population are expressed as effect sizes. ${ }^{45}$ The mean effect size of all studies in Figure 1 is -0.77 (s.d. 0.55 ), a strong effect, indicating a substantial lower life satisfaction in people with SCI than in the reference population.

The course of life satisfaction after SCI has rarely been studied. Brickman et al. ${ }^{24}$ compared current life satisfaction early after SCI with a retrospective rating of life satisfaction before SCI on a 1-5 scale and found a large difference: 4.41 before and 2.96 after SCI. Van Koppenhagen et al. ${ }^{14}$ used a 1-6 scale of life satisfaction and reported a mean 5.3 for life before SCI against 4.31 year after SCI. In both the studies, it was, however, commented that the retrospective scores appear too high and probably suffer from a nostalgia effect.

Only five longitudinal studies in the first year after SCI are available. Three of these studies ${ }^{46-48}$ reported a stable course of life satisfaction. The time span of these studies varied between the first 6 months after discharge, ${ }^{46} 3-15$ months after discharge ${ }^{48}$ and 1 year up to 5 years after SCI, ${ }^{47}$ thereby not covering the period of initial rehabilitation. In a small study by Stensman, ${ }^{9} 17$ patients were followed from 6 months up to 5 years after SCI, and were asked at each administration for their

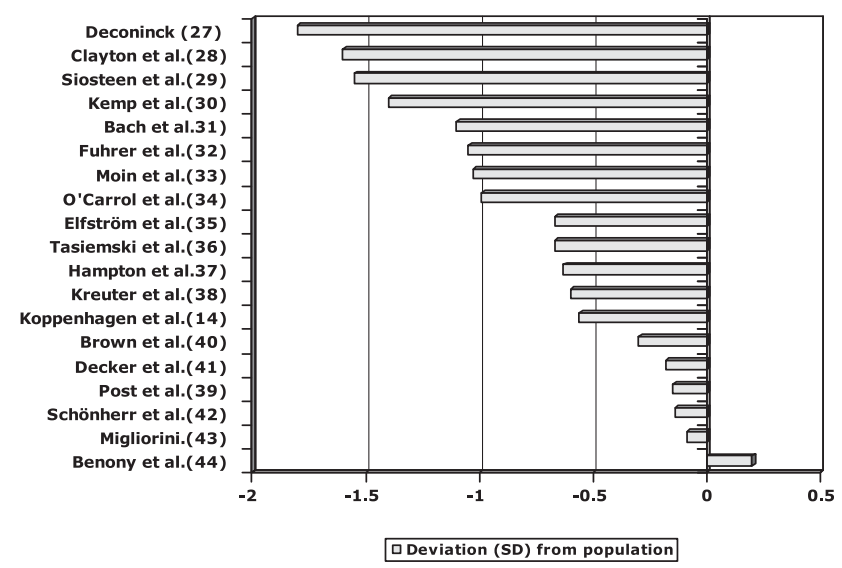

Figure 1 Life satisfaction of people with $\mathrm{SCl}$ compared with population figures expressed as standardized differences (effect size). overall QoL in the previous 6 months. Mean QoL ratings of most subjects improved between 6 months and 1 year after SCI and remained relatively stable after the first year. ${ }^{9}$ Similarly, a Dutch prospective cohort study ${ }^{49}$ showed that life satisfaction improved during inpatient rehabilitation, especially during the first 3 months of active rehabilitation (which started at a mean time of 2 months after injury), remained stable during the first year after discharge. It thus appears that life satisfaction improves from an initial low level early after SCI, but only to a level substantially below that of the general population.

However, average scores can obscure individual differences. Stens$\operatorname{man}^{9}$ found four distinct patterns of life satisfaction early after SCI: low, high, recovery and fluctuating. A larger study ${ }^{10}$ using statistical modelling showed five distinct trajectories from the start of active rehabilitation to 5 years after discharge: low life satisfaction scores at each time point $(27.2 \%)$, high life satisfaction at each time point $(16.5 \%)$, a recovery trajectory $(23.3 \%)$, a deterioration trajectory (2.4\%) and an intermediate life satisfaction trajectory $(30.6 \%)$ that included less distinctive or variable patterns of life satisfaction. ${ }^{10}$

Satisfaction with different life domains has also been the subject of research. Kemp and Krause $^{30}$ studied 177 people with SCI using a 1-4 point scale and found highest satisfaction scores with housing (3.5), friendships (3.2), emotional health (3.2) and life as a whole (3.2), and least satisfaction with health (2.4), finances (2.9) and community life (2.9). Van Koppenhagen et al. ${ }^{14}$ compared five European studies in which the Life Satisfaction Questionnaire (LiSat-9) was used (Table 1). ${ }^{14,36,39,42,50}$ People with SCI were most satisfied with their relationships with partner (4-5.1), family (4.7-5.1), friends (4.5-5.2), and least satisfied with their sexual life (2.7-3.3). Similar results have been reported from a large longitudinal study in the US. ${ }^{51}$

\section{Mental health of people with SCI}

Conceptual and methodological problems hamper research to mental health of people with SCI. ${ }^{52}$ In the early phase of SCI, it is difficult to distinguish between temporary depressed mood and a persistent adjustment disorder. Questionnaires used to measure mental health disorders have not been developed for use in people with SCI, so that some of the items might reflect physical consequences of SCI instead of mental problems. Further, these questionnaires have been developed to screen for mental health disorders, and a score above a certain cutoff point only indicates a possible or probable mental health disorder. A clinical diagnosis, however, can only be made in a clinical diagnostic interview. The cutoff point of screening measures is determined by not missing people with depression (high sensitivity), so that, consequently, part of the people identified with a possible mental health disorder are not diagnosed as such in a subsequent clinical interview (low specificity). We collected figures on the prevalence of depression, anxiety and post-traumatic stress disorder (PTSD) in people with SCI reported in studies published in 2000 or later (Tables 2, 3 and 4).

Depression has been the subject of many studies, showing a wide range of estimates, from 8.8 up to $60 \%$ (Table 2). ${ }^{23,43,46,53-70}$ These estimates are affected by the type of instruments, choice of cutoff point (for example, possible, probable and major) and sample characteristics (gender, age and time after SCI). Craig $(2009)^{5}$ found five studies that applied a structured diagnostic interview during the rehabilitation or hospitalization phase, reporting $20-43 \%$ having minor or major depression disorder. No studies were found applying such an interview after completion of rehabilitation. ${ }^{5}$ Studies using the Patient Health Questionnaire (PHQ-9) yielded lower estimates than studies using the Beck Depression Inventory. Despite these differences, 
Table 1 Comparison of LiSat-9 scores after spinal cord injury in five different studies

\begin{tabular}{|c|c|c|c|c|c|c|c|c|c|c|}
\hline & \multicolumn{2}{|c|}{ The Netherlands ${ }^{14}(\mathrm{~N}=147)$} & \multicolumn{2}{|c|}{ The Netherlands $42(\mathrm{~N}=57)$} & \multicolumn{2}{|c|}{ The Netherlands ${ }^{39}(\mathrm{~N}=318)$} & \multicolumn{2}{|c|}{ Sweden ${ }^{50}(\mathrm{~N}=192)$} & \multicolumn{2}{|c|}{$U K^{36}(\mathrm{~N}=985)$} \\
\hline & Mean & s.d. & Mean & s.d. & Mean & s.d. & Mean & s.d. & Mean & s.d. \\
\hline Life as a whole & 4.3 & 1.3 & 4.6 & 1.0 & 4.4 & 1.2 & 4.2 & 1.2 & 4.2 & 1.3 \\
\hline Leisure situation & 4.6 & 1.2 & 4.7 & 1.3 & 4.4 & 1.3 & 4.2 & 1.3 & 3.9 & 1.4 \\
\hline Vocational situation & 4.1 & 1.4 & 4.3 & 1.6 & 3.8 & 1.7 & 4.1 & 1.3 & 3.7 & 1.5 \\
\hline Financial situation & 4.4 & 1.4 & 4.3 & 1.2 & 4.1 & 1.4 & 4.6 & 1.2 & 3.8 & 1.4 \\
\hline Family life & 5.1 & 1.0 & 5.1 & 1.1 & 4.8 & 1.2 & 4.7 & 1.3 & 4.8 & 1.4 \\
\hline Contact friends & 5.2 & 1.0 & 5.0 & 1.3 & 4.7 & 1.0 & 4.6 & 1.4 & 4.5 & 1.4 \\
\hline
\end{tabular}

Table 2 Prevalence of depression in persons with spinal cord injury

\begin{tabular}{|c|c|c|}
\hline & Prevalence (\%) & Prevalence (\%) \\
\hline Older Adult Health and Mood & Score 6-10 (significant & Score 11-22 \\
\hline Questionnaire & symptomatology) & (possible MDD) \\
\hline Krause et al. ${ }^{53}$ & 24 & 24 \\
\hline Kemp et al. ${ }^{54}$ & 20 & \\
\hline Patient Health Questionnaire-9 & Score $\geqslant 10$ & Probable MDD \\
\hline Bombardier et al. ${ }^{55}$ & 22 & 11.4 \\
\hline Kalpakjian and Albright ${ }^{56}$ & 18.5 & 8.8 \\
\hline Richardson and Richards ${ }^{57}$ & $12-21^{a}$ & \\
\hline Krause et al. ${ }^{58}$ & 19 & 11.7 \\
\hline Hoffman et al. ${ }^{59}$ & $18-21^{a}$ & \\
\hline Fann et al. ${ }^{60}$ & 23 & 12 \\
\hline Hospital Anxiety and Depression & Possible case $(\geqslant 8)$ & Probable case \\
\hline Scale-Depression score & & $(\geqslant 10)$ \\
\hline Woolrich et al. ${ }^{61}$ & 21 & \\
\hline Kennedy et al. ${ }^{62}$ & 26 & \\
\hline Kennedy et al. ${ }^{63}$ & $16.9-26.3^{b}$ & \\
\hline Kennedy et $a l^{23}$ & 41.7 & 25.2 \\
\hline Beck Depression Inventory & & $\begin{array}{c}\text { Clinical range } \\
(\geqslant 14)\end{array}$ \\
\hline Kennedy and Rogers ${ }^{64}$ & & $25-35^{c}$ \\
\hline \multirow[t]{2}{*}{ Kennedy and Rogers ${ }^{46}$} & & $27-60^{b}$ \\
\hline & & $14-35^{a}$ \\
\hline Kennedy and Evans ${ }^{65}$ & & 37 \\
\hline Beedie and Kennedy ${ }^{66}$ & & $26-42^{b}$ \\
\hline Lude et al. ${ }^{67}$ & & $17-32^{d}$ \\
\hline Pollard and Kennedy ${ }^{68}$ & & $35-38^{c}$ \\
\hline \multicolumn{3}{|l|}{ Other measures } \\
\hline Craig et al. ${ }^{69}$ & POMS & 18.2 \\
\hline Migliorini and Tonge ${ }^{43}$ & DASS-21 & $37 * * * *$ \\
\hline Dryden et al. ${ }^{70}$ & ICD-9-CM codes from files & 28.9 \\
\hline
\end{tabular}

Abbreviations: DASS-21, Depression Anxiety Stress

Scale-21-Depression; ICD-9-CM codes: the International Classification of Diseases, 9th Scale-21-Depression; ICD-9-CM codes: the International Classification of Diseases, 9th
Revision, Clinical Modification; MDD, Major Depressive Disorder; POMS, Profile of Mood States. aseveral measurement occasions after discharge.

bSeveral measurement occasions during rehabilitation.

'Several measurement occasions during rehabilitation and after discharge.

dSamples from four different European countries.

${ }^{* * * *}$ Cutoff not reported.

most figures range between 20 and 30\%, showing elevated possible/ probable depression in people with SCI compared with population figures. However, these figures also show that most people with SCI fall well within the normal range.
Table 3 Prevalence of anxiety in persons with spinal cord injury

\begin{tabular}{lc}
\hline Hospital Anxiety and Depression Scale-Anxiety & Possible case ( $\geqslant 8$ ) \\
\hline Woolrich et al. ${ }^{61}$ & 32 \\
Kennedy et al. ${ }^{62}$ & 35 \\
Kennedy et al. ${ }^{63}$ & $13.2-19.7^{\mathrm{a}}$ \\
State-Trait Anxiety Inventory-State & \\
Kennedy and Rogers ${ }^{64}$ & Clinical range (>48) \\
Kennedy and Evans & $20-35^{\mathrm{b}}$ \\
& 41.1 \\
Depression Anxiety Stress Scale-21-Anxiety & Cutoff not reported \\
Migliorini and Tonge & 30
\end{tabular}

aseveral measurement occasions during rehabilitation.

bSeveral measurement occasions during rehabilitation and after discharge.

The course of depression after SCI is unclear. One study in inpatient rehabilitation found a decline of depression scores between 6 and 12 weeks after SCI, ${ }^{63}$ but other studies showed an increase of depression with increased length of rehabilitation, ${ }^{64}$ or did not find any change associated with the duration of inpatient rehabilitation. ${ }^{71}$ The latter study, however, did show decreased depressed mood with decreasing time remaining until discharge. ${ }^{71}$ A longitudinal study from the SCI Model Systems ${ }^{59}$ revealed similar proportions of people with probable major depressive disorder at 1 year after injury $(20.6 \%)$ and at 5 years after injury (18.1\%), although there was considerable individual change in depression status over time. A cross-sectional SCI Model Systems study ${ }^{57}$ reported similar percentages of 20.7 at 1 year and 17.6 at 5 years after injury, but lower percentages of 12.1 at 15 years and 12.3 at 25 years after injury, suggesting a decrease of depressive symptoms over many years.

Anxiety has been examined in six studies (Table 3). ${ }^{43,61-65}$ Proportions with clinically significant symptoms range from 13.2 up to $40 \%$. Kennedy et al., ${ }^{63,64}$ used longitudinal designs during and after initial inpatient rehabilitation, and did not find a consistent course of anxiety over time.

PTSD was examined in 10 studies (Table 4). ${ }^{43,58,65,67,72-78}$ Estimates of the prevalence of PTSD vary widely, from 7.1 up to $61.8 \%$. The highest estimate, however, probably results from using the subscale cutoff point for the total score. ${ }^{72}$ Most studies showed lower prevalence $(7.1-26.6 \%)$. The one longitudinal study showed no association between PTSD and time after SCI, but this study was small and suffered from substantial loss to follow-up. ${ }^{78}$

\section{Psychological factors associated with SWB after SCI}

A recent review ${ }^{18}$ of psychological factors associated with mental health and life satisfaction after SCI included 48 studies, and their 
Table 4 Prevalence of PTSD in persons with spinal cord injury

\begin{tabular}{|c|c|}
\hline Study & Cutoff prevalence (\%) \\
\hline Impact of Events Scale & $\geqslant 20$ \\
\hline Hatcher et al. ${ }^{72}$ & 61.8 \\
\hline Kennedy and Evans ${ }^{65}$ & $\begin{array}{l}\text { IES-I: } 20 \\
\text { IES-A: } 22.4\end{array}$ \\
\hline Lude et al. ${ }^{67}$ & $\begin{array}{l}\text { IES-I: } 7.1-15.3^{\mathrm{a}} \\
\text { IES-A: } 8.6-18.8^{\mathrm{a}}\end{array}$ \\
\hline \multicolumn{2}{|l|}{ Impact of Events Scale-Revised } \\
\hline Migliorini and Tonge ${ }^{43}$ & 8.4 \\
\hline \multicolumn{2}{|l|}{ Posttraumatic Stress Disorder Checklist } \\
\hline Chung et al. ${ }^{73}$ & $\begin{array}{l}44 \text { Full blown } \\
42 \text { Partial }\end{array}$ \\
\hline \multicolumn{2}{|l|}{ Posttraumatic Diagnostic Scale } \\
\hline Agar et al. ${ }^{74}$ & 24 \\
\hline Boyer et al. ${ }^{75}$ & $\begin{array}{l}\text { 25.4 PTSD } \\
\text { 20.9 Partial PTSD }\end{array}$ \\
\hline \multicolumn{2}{|c|}{ Purdue Posttraumatic Stress Disorder Scale_Revised } \\
\hline Krause et al. ${ }^{58}$ & 7.2 \\
\hline $\begin{array}{l}\text { Clinician Administered PTSD Scale } \\
\text { Radnitz et al. }{ }^{76}\end{array}$ & $\begin{array}{l}\text { Moderate threshold } \\
26.6 \text { Lifetime } \\
\text { 16.1 Current }\end{array}$ \\
\hline \multicolumn{2}{|l|}{ Havard Trauma Questionnaire } \\
\hline Nielsen et al. ${ }^{77}$ & $\begin{array}{l}\text { 7.1 Case } \\
\text { 10.7 Partial case }\end{array}$ \\
\hline Nielsen et al. ${ }^{78}$ & 18.4-22.5 Case ${ }^{\mathrm{b}}$ \\
\hline
\end{tabular}

Abbreviation: PTSD, post-traumatic stress disorder.

aSamples from four different European countries.

bDifferent measurement occasions during in-patient rehabilitation and after discharge.

results are summarized here. Psychological variables were classified as consistent determinants if all bivariate associations reported were statistically significant and if most of these associations were moderate (0.3-0.5) or stronger. Variables were classified as inconsistent determinants if only some of the associations were statistically significant or if most significant associations were weak. Variables were classified as unrelated to mental health and life satisfaction if all, or nearly all, associations were nonsignificant.

Factors consistently associated with SWB were as follows: perceived control in life (range of correlations 0.49-0.69), experienced sense of coherence (0.32-76), endorsed positive factors such as hope (0.27-0.64) and purpose in life $(0.50-0.71)$, reported feelings of selfworth such as self-efficacy (0.23-0.62) and self-esteem (0.33-0.73), reported positive $(0.42-0.52)$ and negative $(0.35-0.73)$ affect, and reported posttraumatic cognitions $(0.35-0.66)$.

Factors inconsistently related to SWB included appraisals (17 out of $21(17 / 21)$ correlations were statistically significant and 13 correlations were $>0.30)$, subscales of locus of control $(6 / 15,2>0.30)$, attribution of blame $(8 / 19 ; 2>0.30)$, spirituality $(3 / 12 ; 3>0.30)$, personality characteristics $(5 / 15 ; 3>0.30)$, emotion-focused coping styles (30/ $51 ; 20>0.30)$ and passive coping styles $(31 / 57 ; 27>0.30)$. Of all the attribution of blame variables, self-blame and perceived avoidability of the SCI were most frequently, but weakly, associated with SWB. For spirituality, research has focused more on religious than existential aspects, yet existential spirituality was strongly associated with SWB in one study. Personality variables were only examined in two studies, and only neuroticism and extraversion were associated with SWB.
Factors not associated with SWB included several coping variables. Although acceptance was a consistent determinant of SWB, the majority of emotion-focused coping styles were not associated with SWB. Of the passive coping styles, only helplessness was consistently related to SWB. Although behavioural disengagement, denial, avoidance and social reliance were moderately to strongly related to SWB in some studies, they were not consistently related to SWB across studies. Few significant associations $(12 / 57 ; 9>0.30)$ between active problemfocused coping and SWB outcomes were found. An explanation for the lack of associations between active coping and SWB might be that in situations where goals are blocked, such as is the case with an SCI, adjusting personal preferences and goals to situational changes is more effective and more positively related to adjustment than actively adjusting life circumstances to one's personal preferences. ${ }^{79}$

Social support factors associated with SWB after SCI

Social support is defined as an exchange of resources between individuals intended to enhance the well-being of the recipient. ${ }^{80}$ It conveys the information of being loved, cared for, esteemed, valued and of belonging. ${ }^{81}$ Different dimensions of social support are type, source, and qualifier. Types of social support are instrumental (for example, tangible assistance), emotional (for example, exchange with a close friend) and informational (for example, advice from a peer). Sources of social support can be family members, in particular the spouse, and friends and acquaintances, and others. Support by professionals is also included in some social support measures. ${ }^{82}$ Social support can be described from a quantitative (for example, network size) or qualitative (for example, satisfaction with support) perspective.

Marriage is a major source of support and well-being. ${ }^{83}$ Unfortunately, US figures showed that the majority of people with SCI $(54.2 \%)$ are single at discharge from rehabilitation, and divorce rates in people with SCI are higher compared with the population of the same age and gender. ${ }^{84}$ Another SCI Model Systems study showed that the proportion of married people with SCI varied from $31 \%$ at 5 years post SCI to $43 \%$ at 25 years post SCI. ${ }^{85}$ Kreuter et al. ${ }^{38}$ reported $37.7 \%$ married or cohabiting people with SCI in Sweden. Estimates of married or cohabitating people with SCI in the Netherlands are much higher, from $56.3 \%{ }^{13}$ up to $65.9 \% .^{86}$

A recent review identified no less than 58 studies about social support and SCI. ${ }^{19}$ Seven studies reported 10 out of 17 associations between social support and life satisfaction to be significant (10/17; $8>0.30)$. Further, 14 studies reported 48 out of 60 associations between social support and mental health problems to be significant $(48 / 60 ; 31<-0.30) .{ }^{19}$ Satisfaction with social support was more strongly related to mental health (range -0.19 to -0.59 ) than the reported quantity of support $(0.04$ to -0.30$){ }^{64,66,74,87,88}$ Three studies using the Social Provisions Scale found the scale Reassurance of Worth and Social Integration to be most strongly $(-0.23$ to -0.39$)$ related to mental health ${ }^{89-91}$. Emotion-focused support was more strongly related to life satisfaction $(0.11-0.34)$ than problem-focused support $(-0.09$ to 0.11$){ }^{82}$

\section{Psychosocial interventions to enhance SWB after SCI}

Psychological interventions for treatment of depression following SCI have been targeted at coping with pain or pain cognitions, or both. ${ }^{52,92}$ Cognitive behavioural therapy (CBT) incorporates a variety of techniques to facilitate emotional and behavioural change on the part of the person. ${ }^{92}$ CBT can include addressing 'irrational' or negative thoughts, increasing opportunities for participating in rewarding activities and instruction in relaxation. Issues of 
Table 5 Studies evaluating interventions to enhance mental health of persons with spinal cord injury

\begin{tabular}{|c|c|c|c|c|c|}
\hline Author & $\begin{array}{l}\text { Study } \\
\text { design }\end{array}$ & Type of intervention & Size & $\begin{array}{l}\text { Change of } \\
\text { depression }\end{array}$ & Treatment effect \\
\hline Dorstyn et al. ${ }^{93}$ & $\mathrm{CT}$ & $\begin{array}{l}\text { Individual CBT, fortnightly sessions of } \\
30-60 \mathrm{~min}\end{array}$ & $\begin{array}{l}\text { Intervention: } 11 \\
\text { Control: } 13 \text { (without distress) }\end{array}$ & $\begin{array}{l}\text { Decrease (NS) } \\
\text { No change }\end{array}$ & Not tested \\
\hline Craig et al. ${ }^{94}$ & $\mathrm{CT}$ & $\begin{array}{l}\text { CBT in small groups, } 10 \text { weeks, } 1.5-2 \mathrm{~h} \\
\text { a week }\end{array}$ & $\begin{array}{l}\text { Intervention: } 28 \\
\text { Control: } 41 \text { (not treated with CBT) }\end{array}$ & $\begin{array}{l}\text { Decrease } \\
\text { Decrease }\end{array}$ & $\begin{array}{l}\text { NS } \\
\text { Significant in subgroup }\end{array}$ \\
\hline King and Kennedy 95 & CT & $\begin{array}{l}\text { CET in small groups, } 7 \text { sessions twice a week } \\
\text { for } 60-75 \mathrm{~min}\end{array}$ & $\begin{array}{l}\text { Intervention: } 19 \\
\text { Control: } 19 \text { (historic controls) }\end{array}$ & $\begin{array}{l}\text { Decrease } \\
\text { No change }\end{array}$ & Significant over-all \\
\hline Kennedy et al. ${ }^{96}$ & $\mathrm{CT}$ & $\begin{array}{l}\text { CET in small groups, } 7 \text { sessions twice a week } \\
\text { for } 60-75 \mathrm{~min}\end{array}$ & $\begin{array}{l}\text { Intervention: } 45 \\
\text { Control: } 40 \text { (historic controls) }\end{array}$ & $\begin{array}{l}\text { Decrease } \\
\text { No change }\end{array}$ & NS $(P=0.058)$ \\
\hline Dutchnick et al. ${ }^{97}$ & $\mathrm{RCT}$ & $\begin{array}{l}\text { CET versus supportive group therapy in } \\
\text { weekly sessions }\end{array}$ & $\begin{array}{l}\text { Intervention: } 16 \\
\text { Control: } 17\end{array}$ & $\begin{array}{l}\text { Decrease } \\
\text { Decrease }\end{array}$ & NS \\
\hline Kemp et al. ${ }^{54}$ & $\mathrm{CT}$ & CBT combined with medication & $\begin{array}{l}\text { Intervention: } 28 \\
\text { Control: } 15 \text { (declined treatment) }\end{array}$ & $\begin{array}{l}\text { Decrease } \\
\text { No change }\end{array}$ & Not tested \\
\hline
\end{tabular}

Abbreviations: CBT, cognitive behavioural therapy; CET, coping effectiveness training; CT, controlled trial; NS, nonsignificant; RCT, randomized controlled trial.

assertiveness, social skills and discussions of sexuality have also been included. Employing a group setting to provide CBT can also be a cost-effective opportunity for peer support, practice of social skills and the opportunity for gaining additional viewpoints. ${ }^{52}$ We found six psychological intervention studies primarily aimed at improving mental health of people with SCI (Table 5). ${ }^{54,93-97}$ The study design of most studies was weak; only one was a randomized controlled trial. ${ }^{97}$ Other studies used people as controls who were treated in earlier years or elsewhere, ${ }^{94-96}$ who were not eligible for the intervention $^{93}$ or who declined the intervention. ${ }^{54} \mathrm{~A}$ significant treatment effect (interaction between group and time) was demonstrated by only one study evaluating coping effectiveness training (CET).${ }^{95}$ However, the subsequent larger study with the same design and intervention found only a borderline treatment effect. ${ }^{96}$ On the positive side, all studies showed a significant decrease of depressive symptoms during the intervention, although this effect was not always maintained at follow-up. ${ }^{93}$ In one study, ${ }^{94}$ subgroup analyses showed that for people with baseline levels of depression in the clinical range, the CBT group improved more than the control group, suggesting that CBT might be more effective in people with more severe mental health disorders.

Only one study examined possible mechanisms of treatment. ${ }^{96}$ Decrease of anxiety and depression but no change of coping strategies were found after CET. The authors hypothesized that their intervention might have worked by changing participants' negative appraisals of the implications of SCI, increasing the perceived manageability of its consequences, thereby improving mood. ${ }^{96}$

One randomized controlled trial provided supportive group therapy (SGT) to the comparison group. ${ }^{97}$ SGT consisted of minimally structured, emotion-focused SGT sessions. Sixty-minute sessions were provided weekly, and members were encouraged to attend until discharged. SGT sessions emphasized sharing of experiences and information surrounding injury-related topics, exploration of emotional and cognitive reactions, and the opportunity for support and education from peers and psychologists. SGT may be equally effective in reducing depression and anxiety as CET. ${ }^{97}$

\section{DISCUSSION}

The present paper reviewed the literature on SWB and the relationships between psychological and social support factors and SWB in people with SCI in order to identify gaps in scientific knowledge and recommend research priorities. The results clearly showed that the prevalence of depression, anxiety and PTSD is elevated in people with chronic SCI, and that their average life satisfaction is substantially below that of the general population. These findings confirm and expand on earlier results, ${ }^{14}$ and underscores the importance of studying SWB as a long-term outcome of $\mathrm{SCI}^{85}$ and as an outcome of intervention studies. ${ }^{98}$

In this review, a large variation in SWB results between studies has been found. The factors contributing to this variation are unclear, but probably include variation in measures, in/exclusion criteria, setting and reference populations. The large majority of published studies are from the United States, Canada and Northern and Western Europe. There is a lack of studies providing information on people with SCI elsewhere in the world, as SWB results may not generalize to other countries and cultures. Even fewer studies have compared samples across countries. ${ }^{99,100}$ It is recommended to perform SWB studies in countries currently not well represented in this review and to perform comparisons between countries and cultures.

With respect to the course of life satisfaction after SCI, the results showed that at group level, life satisfaction improves from a low level early after SCI, and that there is no substantial decrease of life satisfaction at long-term follow-up. ${ }^{51,86}$ Distinct trajectories in the course of life satisfaction have been identified using two simple life satisfaction questions, ${ }^{13}$ suggesting the possibility of systematic screening on the risk of long-term adjustment problems. However, few other studies into life satisfaction in an in-patient setting have been performed to date, and this finding needs empirical confirmation.

Conflicting findings have been reported in the few studies on the course of mental health in initial inpatient rehabilitation. One factor that might explain these inconsistencies is length of stay; longer stays $^{63,64}$ are more likely to be associated with change in mental health in either direction compared with shorter stays. ${ }^{71}$ Further, time can be included in the analysis in different ways, A study showed no association between time after admission and depressed mood, but did show an association between duration until discharge and depressed mood. ${ }^{71}$ Finally, results can be influenced by selective drop out: in the study showing increase of depression with longer duration of rehabilitation, ${ }^{64}$ the sample size decreased with each subsequent administration. Likely, people staying longer in the rehabilitation hospital are the people who suffer from more severe injuries and more and more severe complications. Therefore, composition of the sample instead of duration of rehabilitation might explain the 
increase in depression scores with longer duration of rehabilitation in this group.

There is considerable evidence on the role of psychological factors in SWB. Perceived control, resilience, sense of coherence, self-worth, hope and purpose in life are consistently associated with QoL after SCI. These findings suggest the potential of positive psychology interventions aimed at strengthening internal resources of people with SCI. ${ }^{101}$

Interestingly, one of the most popular topics among psychologists, coping behaviours, showed much less consistent results, warranting further study. Psychological terminology is inconsistent, especially with respect to coping and appraisals. ${ }^{18} \mathrm{~A}$ second limitation is the conceptual proximity between dependent and independent variables. Other limitations concern the wide variety of questionnaires used and the overrepresentation of small studies and of studies with a crosssectional design. ${ }^{18}$ Longitudinal studies with sufficient sample size, harmonizing the use of measures, and more clearly specified and operationalized constructs are needed. More research is also needed to measure psychological and social factors early after SCI to test the predictive value of these factors for long-term adjustment, and to better understand which people are resilient to a SCI and which people are not. With respect to this last point, it might also be useful to test how different psychosocial factors are related to each other by making use of structural equation models. ${ }^{102}$

Little is known about the contribution of psychological support for people with SCI, and instruments to describe this support have only recently been introduced. ${ }^{103}$ Resources to provide psychological support are limited in most settings, so that it is important to document its contents and outcomes, including longitudinal studies using qualitative or observational designs. Promising results were reported with respect to intervention studies, but the effectiveness of psychological interventions has not been established to date. The available studies used small samples, usually lacked patient randomization and showed inconsistent results. The recent review on the effectiveness of CBT by the Spinal Cord Injury Rehabilitation Evidence (SCIRE) team, however, came to a more positive conclusion. ${ }^{92}$ That review included three studies that were excluded in the current review, among which the only study providing level 1 evidence, ${ }^{104}$ because these studies either included people with various chronic conditions, ${ }^{105}$ were targeted at caregivers of people with $\mathrm{SCI},{ }^{104}$ or the data overlapped with those in a later publication. ${ }^{94,106}$ A second difference is that the SCIRE review focused more on the size of treatment effects in the intervention groups than on statistical significance between intervention and control groups. ${ }^{92}$

All intervention studies found sought to minimize distress (depression and anxiety) and none targeted life satisfaction. Only one study included a social support intervention, which showed similar effectiveness like the CET intervention. A further intervention study that targeted patients and caregivers also showed effectiveness. ${ }^{104,107}$ A variety of intervention studies are, therefore, needed to identify optimal psychological support for people with SCI. In particular, studies are needed in the chronic phase of SCI, studies that target to strengthen personal resources of people with $\mathrm{SCI}^{101}$ and studies that target to support the family of people with SCI. ${ }^{107}$

\section{CONCLUSION}

There is a need for cohort studies with sufficient sample size, which include people early after onset of SCI and assess physical and psychosocial factors to enhance our understanding of the course of SWB and its predictors after SCI. This would enable the identification of people who are at risk of long-term impairment of SWB. Finally, psychosocial intervention studies are needed to identify which interventions may improve SWB of people with SCI.

\section{CONFLICT OF INTEREST}

The authors declare no conflict of interest.

1 Strauss DJ, DeVivo MJ, Paculdo DR, Shavelle RM. Trends in life expectancy after spinal cord injury. Arch Phys Med Rehabil 2006; 87: 1079-1085.

2 Dijkers MP. Quality of life of individuals with spinal cord injury: a review of conceptualization, measurement, and research findings. J Rehabil Res Dev 2005; 42: 87-110.

3 Post M, Noreau L. Quality of life after spinal cord injury. J Neurol Phys Ther 2005; 29: 139-146.

4 North NT. The psychological effects of spinal cord injury: a review. Spinal Cord 1999; 37: 671-679.

5 Craig A, Tran Y, Middleton J. Psychological morbidity and spinal cord injury. Spinal Cord 2009; 47: 108-114.

6 Hill MR, Noonan VK, Sakakibara BM, Miller WC. Quality of life instruments and definitions in individuals with spinal cord injury: a systematic review. Spinal Cord 2010; 48: 438-450.

7 Hunt SM. The problem of quality of life. Qual Life Res 1997; 6: 205-212.

8 Post M, De Witte L, Schrijvers A. Quality of life and the ICIDH: towards an integrated conceptual model for rehabilitation outcomes research. Clin Rehabil 1999. 13: 5-15.

9 Diener E. The science of happiness and a proposal for a national index. Am Psychol 2000; 55: 34-43.

10 van Leeuwen CM, Post MW, Westers $\mathrm{P}$, van der Woude $\mathrm{LH}$, de Groot $\mathrm{S}$, Sluis T et al. Relationships between activities, participation, personal factors, mental health, and life satisfaction in persons with spinal cord injury. Arch Phys Med Rehabill 2012; 93: 82-89.

11 Brickman $P$, Coates D, Janoff-Bulman R. Lottery winners and accident victims: is happiness relative? J Pers Soc Psychol 1978; 36: 917-927.

12 Stensman R. Adjustment to traumatic spinal cord injury: a longitudinal study of selfreported quality of life. Paraplegia 1994; 32: 416-422.

13 van Leeuwen CM, Post MW, Hoekstra T, van der Woude LH, de Groot S, Snoek GJ et al. Trajectories in the course of life satisfaction after spinal cord injury: identification and predictors. Arch Phys Med Rehabil 2011; 92: 207-213.

14 Dijkers M. Quality of life after spinal cord injury: a meta analysis of the effects of disablement components. Spinal Cord 1997; 35: 829-840.

15 Dijkers MP. Correlates of life satisfaction among persons with spinal cord injury. Arch Phys Med Rehabil 1999; 80: 867-876.

16 Post MW, de Witte LP, van Asbeck FW, van Dijk AJ, Schrijvers AJ. Predictors of health status and life satisfaction in spinal cord injury. Arch Phys Med Rehabil 1998; 79: 395-401.

17 van Koppenhagen CF, Post MW, van der Woude LH, de Groot S, de Witte LP, van Asbeck FW et al. Changes and determinants of life satisfaction after spinal cord injury: a cohort study in The Netherlands. Arch Phys Med Rehabil 2008; 89: 1733-1740.

18 van Leeuwen CM, Kraaijeveld S, Post MW, Lindeman E. Associations between psychological variables and quality of life in persons with spinal cord injury: a systematic review. Spinal Cord, (e-pub ahead of print November 2011; doi: 10.1038/sc.2011.120)

19 Müller R, Peter C, Cieza A, Geyh S. The role of social support and social skills in people with spinal cord injury - A systematic review of the literature. Spinal Cord 2011 (e-pub ahead of print 18 October; doi: 10.1038/sc.2011.116).

20 Charlifue SW, Weitzenkamp DA, Whiteneck GG. Longitudinal outcomes in spinal cord injury: aging, secondary conditions and well-being. Arch Phys Med Rehabil 1999; 80: 1429-1434.

21 Richards JS, Bombardier CH, Tate D, Dijkers M, Gordon W, Shewchuk R et al. Access to the environment and life satisfaction after spinal cord injury. Arch Phys Med Rehabil 1999; 80: 1501-1506.

22 van Leeuwen CM, Post MW, van Asbeck FW, van der Woude LH, de Groot S, Lindeman E. Social support and life satisfaction in spinal cord injury during and up to 1 year after inpatient rehabilitation. J Rehabil Med 2010; 42: 265-271.

23 Kennedy P, Lude P, Elfström ML, Smithson EF. Psychological contributions to functional independence: a longitudinal investigation of spinal cord injury rehabilitation. Arch Phys Med Rehabil 2011; 92: 597-602.

24 Jensen MP, Moore MR, Bockow TB, Ehde DM, Engel JM. Psychosocial factors and adjustment to chronic pain in persons with physical disabilities: a systematic review. Arch Phys Med Rehabil 2011; 92: 146-160.

25 Voerman GE, Erren-Wolters CV, Fleuren JF, Hermens HJ, Geurts AC. Perceived spasticity in chronic spinal cord injured patients: associations with psychological factors. Disabil Rehabil 2010; 32: 775-780.

26 Saunders LL, Krause JS. Personality and behavioral predictors of pressure ulcer history. Top Spinal Cord Inj Rehabil 2010; 16: 61-71.

27 Deconinck H. The health condition of spinal cord injuries in two Afghan towns. Spinal Cord 2003; 41: 303-309.

28 Clayton KS, Chubon RA. Factors associated with the quality of life of long-term spinal cord injured persons. Arch Phys Med Rehabil 1994; 75: 633-638. 
29 Siosteen A, Lundqvist C, Blomstrand C, Sullivan L, Sullivan M. The quality of life of three functional spinal cord injury subgroups in a Swedish community. Paraplegia 1990; 28: 476-488.

30 Kemp BJ, Krause JS. Depression and life satisfaction among people ageing with postpolio and spinal cord injury. Disabil Rehabil 1999; 21: 241-249.

31 Bach JR, Tilton MC. Life satisfaction and well-being measures in ventilator assisted individuals with traumatic tetraplegia. Arch Phys Med Rehabil 1994; 75: 626-632.

32 Fuhrer MJ, Rintala DH, Hart KA, Clearman R, Young ME. Relationship of life satisfaction to impairment, disability, and handicap among persons with spinal cord injury living in the community. Arch Phys Med Rehabil 1992; 73: 552-557.

33 Moin V, Duydevany EI, Mazor ED. Sexual identity, body image and life satisfaction among women with and without physical disability. Sex Disabil 2009; 27: 83-95.

34 O'Carroll R, Ayling R, O'Reilly S, North N. Alexithymia and sense of coherence in patients with total spinal cord transection. Psychosom Med 2003; 65: 151-155.

35 Elfström M, Ryden A, Kreuter M, Taft C, Sullivan M. Relations between coping strategies and health-related quality of life in patients with spinal cord lesion. J Rehabil Med 2005; 37: 9-16.

36 Tasiemski T, Kennedy P, Gardner BP, Taylor N. The association of sports and physical recreation with life satisfaction in a community sample of people with spinal cord injuries. NeuroRehabilitation 2005; 20: 253-265.

37 Hampton NZ. Disability status, perceived health, social support, self-efficacy, and quality of life among people with spinal cord injury in the People's Republic of China. Int J Rehabil Res 2001; 24: 69-71.

38 Kreuter M, Sullivan M, Dahllof AG, Siosteen A. Partner relationships, functioning, mood and global quality of life in persons with spinal cord injury and traumatic brain injury. Spinal Cord 1998; 36: 252-261.

39 Post MW, Van Dijk AJ, Van Asbeck FW, Schrijvers AJ. Life satisfaction of persons with spinal cord injury compared to a population group. Scand J Rehabil Med 1998; 30: 23-30.

40 Brown M, Vandergoot D. Quality of life for individuals with traumatic brain injury: comparison with others living in the community. J Head Trauma Rehabil 1998; 13: $1-23$.

41 Decker SD, Schulz R. Correlates of life satisfaction and depression in middle-aged and elderly spinal cord-injured persons. Am J Occup Ther 1985; 39: 740-745.

42 Schonherr MC, Groothoff JW, Mulder GA, Eisma WH. Participation and satisfaction after spinal cord injury: results of a vocational and leisure outcome study. Spinal Cord 2005; 43: 241-248.

43 Migliorini C, Tonge B. Reflecting on subjective well-being and spinal cord injury. $J$ Rehabil Med 2009; 41: 445-450.

44 Benony H, Daloz L, Bungener C, Chahraoui K, Frenay C, Auvin J. Emotional factors and subjective quality of life in subjects with spinal cord injuries. Am J Phys Med Rehabil 2002; 81: 437-445.

45 Cohen J. Statistical Power Analysis for the Behavorial Sciences 2nd edn. Hillsdale: Erlbaum, 1988.

46 Kennedy P, Rogers BA. Reported quality of life of people with spinal cord injuries: a longitudinal analysis of the first 6 months post-discharge. Spinal Cord 2000; 38: 498-503.

47 Putzke JD, Barrett JJ, Richards JS, Underhill AT, Lobello SG. Life satisfaction following spinal cord injury: long-term follow-up. J Spinal Cord Med 2004; 27: $106-110$.

48 Mortenson WB, Noreau L, Miller WC. The relationship between and predictors of quality of life after spinal cord injury at 3 and 15 months after discharge. Spinal Cord 2010; 48: 73-79.

49 van Koppenhagen CF, Post MW, van der Woude LH, de Groot S, de Witte LP, van Asbeck FW et al. Recovery of life satisfaction in persons with spinal cord injury during inpatient rehabilitation. Am J Phys Med Rehabil 2009; 88: 887-895.

50 Budh CN, Osteråker AL. Life satisfaction in individuals with a spinal cord injury and pain. Clin Rehabil 2007; 21: 89-96.

51 Krause J. Adjustment after spinal cord injury: a 9-year longitudinal study. Arch Phys Med Rehabil 1997; 78: 651-657.

52 Orenczuk S, Slivinski J, Mehta S, Teasell RW. Depression following spinal cord injury. In: Eng JJ, Teasell RW, Miller WC et al. (eds). Spinal Cord Injury Rehabilitation Evidence Version 3.0. 2010.

53 Krause JS, Kemp B, Coker J. Depression after spinal cord injury: relation to gender, ethnicity, aging, and socioeconomic indicators. Arch Phys Med Rehabil 2000; 81: 1099-1109.

54 Kemp BJ, Kahan JS, Krause JS, Adkins RH, Nava G. Treatment of major depression in individuals with spinal cord injury. J Spinal Cord Med 2004; 27: 22-28.

55 Bombardier CH, Richards JS, Krause JS, Tulsky D, Tate DG. Symptoms of major depression in people with spinal cord injury: implications for screening. Arch Phys Med Rehabil 2004; 85: 1749-1756.

56 Kalpakjian CZ, Albright KJ. An examination of depression through the lens of spinal cord injury. Comparative prevalence rates and severity in women and men. Womens Health Issues 2006; 16: 380-388.

57 Richardson EJ, Richards JS. Factor structure of the PHQ-9 screen for depression across time since injury among persons with spinal cord injury. Rehabil Psychol 2008; 53: 243-249.

58 Krause JS, Saunders LL, Newman S. Posttraumatic stress disorder and spinal cord injury. Arch Phys Med Rehabil 2010; 91: 1182-1187.

59 Hoffman JM, Bombardier CH, Graves DE, Kalpakjian CZ, Krause JS. A longitudinal study of depression from 1 to 5 years after spinal cord injury. Arch Phys Med Rehabil 2011; 92: 411-418.
60 Fann JR, Bombardier CH, Richards JS, Tate DG, Wilson CS, Temkin N. Depression after spinal cord injury: comorbidities, mental health service use, and adequacy of treatment. Arch Phys Med Rehabil 2011; 92: 352-360.

61 Woolrich RA, Kennedy P, Tasiemski T. A preliminary psychometric evaluation of the Hospital Anxiety and Depression Scale (HADS) in 963 people living with a spinal cord injury. Psychol Health Med 2006; 11: 80-90.

62 Kennedy P, Evans M, Sandhu N. Psychological adjustment to spinal cord injury: the contribution of coping, hope and cognitive appraisals. Psychol Health Med 2009; 14: 17-33.

63 Kennedy P, Lude P, Elfström ML, Smithson E. Cognitive appraisals, coping and quality of life outcomes: a multi-centre study of spinal cord injury rehabilitation. Spinal Cord 2010; 48: 762-769.

64 Kennedy P, Rogers BA. Anxiety and depression after spinal cord injury: a longitudinal analysis. Arch Phys Med Rehabil 2000; 81: 932-937.

65 Kennedy P, Evans MJ. Evaluation of post traumatic distress in the first 6 months following SCI. Spinal Cord 2001; 39: 381-386.

66 Beedie A, Kennedy P. Quality of social support predicts hopelessness and depression post spinal cord injury. J Clin Psychol Med Settings 2002; 9: 227-234.

67 Lude P, Kennedy P, Evans M, Lude Y, Beedie A. Post traumatic distress symptoms following spinal cord injury: a comparative review of European samples. Spinal Cord 2005; 43: 102-108.

68 Pollard C, Kennedy P. A longitudinal analysis of emotional impact, coping strategies and post-traumatic psychological growth following spinal cord injury: a 10-year review. Br J Health Psychol 2007; 12: 347-362.

69 Craig A, Tran Y, Lovas J, Middleton J. Spinal cord injury and its association with negative psychological states. Int J Psychosoc Rehabil 2008; 12: 115-121.

70 Dryden D, Saunders L, Rowe B, May LA, Yiannakoulias N, Svenson LW et al. Depression following traumatic spinal cord injury. Neuroepidemiology 2005; 25: 55-61.

71 Cushman LA, Dijkers M. Depressed mood during rehabilitation of persons with spinal injury. J Rehabil 1991; 57: 35-38.

72 Hatcher M, Whitaker C, Karl A. What predicts post-traumatic stress following spinal cord injury? Br J Health Psychol 2009; 14: 541-561.

73 Chung MC, Preveza E, Papandreou K, Prevezas N. The relationship between posttraumatic stress disorder following spinal cord injury and locus of control. J Affect Disord 2006; 93: 229-232.

74 Agar E, Kennedy P, King N. The role of negative cognitive appraisals in PTSD symptoms following spinal cord injuries. Behav Cogn Psychother 2006; 34: 437-452.

75 Boyer BA, Knolls ML, Kafkalas CM, Tollen LG. Prevalence of posttraumatic stress disorder in patients with pediatric spinal cord injury: relationship to functional independence. Top Spinal Cord Inj Rehabil 2000; 6: 125-133.

76 Radnitz C. Recovery from posttraumatic stress disorder in veterans with spinal cord injury. SCl psychosocial process 2002; 15: 185-197.

77 Nielsen MS. Prevalence of posttraumatic stress disorder in persons with spinal cord injuries: the mediating effect of social support. Rehabil Psychol 2003; 48: 89-295.

78 Nielsen MS. Crisis support and coping as mediators of well-being in persons with spinal cord lesion. J Clin Psychol Med Settings 2003; 10: 91-99.

79 Brandtstädter J, Renner G. Tenacious goal pursuit and flexible goal adjustment: explication and age-related analysis of assimilative and accommodative strategies of coping. Psychol Aging 1990; 5: 58-67.

80 Shumaker S, Brownel A. Toward a theory of social support: closing conceptual gaps. J Soc Issues 1984; 40: 11-36.

81 Cobb S. Social support as a moderator for life stress. Psychosom Med 1976; 38 : 300-314

82 Post MWM, Ros WJG, Schrijvers AJP. Impact of social support on health status and life satisfaction in people with a spinal cord injury. Psychol Health 1999; 14: 679-695.

83 Holicky R, Charlifue S. Ageing with spinal cord injury: the impact of spousal support. Disabil Rehabil 1999; 21: 250-257.

84 DeVivo MJ, Hawkins LN, Richards JS, Go BK. Outcomes of post-spinal cord injury marriages. Arch Phys Med Rehabil 1995; 76: 130-138.

85 Charlifue S, Lammertse DP, Adkins RH. Aging with spinal cord injury: changes in selected health indices and life satisfaction. Arch Phys Med Rehabil 2004; 85: 1848-1853.

86 Bloemen-Vrencken JH, Post MW, Hendriks JM, De Reus EC, De Witte LP. Health problems of persons with spinal cord injury living in the Netherlands. Disabil Rehabil 2005; 27: 1381-1389.

87 Rintala DH, Young ME, Hart KA, Clearman RR, Fuhrer MJ. social support and the wellbeing of persons with spinal cord injury living in the community. Rehabil Psychol 1992; 37: 155-163.

88 Stroud MW, Turner JA, Jensen MP, Cardenas DD. Partner responses to pain behaviors are associated with depression and activity interference among persons with chronic pain and spinal cord injury. J Pain 2006; 7: 91-99.

89 Elliott TR, Herrick SM, Patti AM, Witty TE, Godshall FJ, Spruell M. Assertiveness, social support, and psychological adjustment following spinal cord injury. Behav Res Ther 1991; 29: 485-493.

90 Elliott TR, Herrick SM, Witty TE, Godshall F, Spruell M. Social support and depression following spinal cord injury. Rehabil Psychol 1992; 37: 37-48.

91 Herrick HM, Elliott TR, Crow F. Social support and the prediction of health complications among persons with spinal cord injuries. Rehabil Psychol 1994; 39: 231-250. 
92 Mehta S, Orenczuk S, Hansen KT, Aubut JA, Hitzig SL, Legassic M, Teasell RW. An evidence-based review of the effectiveness of cognitive behavioral therapy for psychosocial issues post-spinal cord injury. Rehabil Psychol 2011; 56: 15-25.

93 Dorstyn DS, Mathias JL, Denson LA. Psychological intervention during spinal rehabilitation: a preliminary study. Spinal Cord 2010; 48: 756-761.

94 Craig AR, Hancock K, Chang E, Dickson H. Immunizing against depression and anxiety after spinal cord injury. Arch Phys Med Rehabil 1998; 79: 375-377.

95 King C, Kennedy P. Coping effectiveness training for people with spinal cord injury: preliminary results of a controlled trial. Br J Clin Psychol 1999; 38: 5-14.

96 Kennedy P, Duff J, Evans M, Beedie A. Coping effectiveness training reduces depression and anxiety following traumatic spinal cord injuries. $\mathrm{Br} J$ Clin Psychol 2003; 42: 41-52.

97 Duchnick JJ, Letsch EA, Curtiss G. Coping effectiveness training during acute rehabilitation of spinal cord injury/dysfunction: a randomized clinical trial. Rehabil Psychol 2009; 54: 123-132.

98 Scherer MJ, Cushman LA. Measuring subjective quality of life following spinal cord injury: a validation study of the assistive technology device predisposition assessment. Disabil Rehabil 2001; 23: 387-393.

99 Ide M, Fugl-Meyer AR. Life satisfaction in persons with spinal cord injury: a comparative investigation between Sweden and Japan. Spinal Cord 2001; 39: 387-393.
100 Krause JS, Saladin LK, Adkins RH. Disparities in subjective well-being, participation, and health after spinal cord injury: a 6-year longitudinal study. NeuroRehabilitation 2009; 24: 47-56.

101 Sin NL, Lyubomirsky S. Enhancing well-being and alleviating depressive symptoms with positive psychology interventions: a practice-friendly meta-analysis. J Clin Psychol 2009; 65: 467-487.

102 McColl MA, Lei H, Skinner H. Structural relationships between social support and coping. Soc Sci Med 1995; 41: 395-407.

103 Wilson C, Huston T, Koval J, Gordon SA, Schwebel A, Gassaway J. SCIRehab Project Series: the psychology taxonomy. J Spinal Cord Med 2009; 32: 319-328.

104 Schulz R, Czaja SJ, Lustig A, Zdaniuk B, Martire LM, Perdomo D. Improving the quality of life of caregivers of persons with spinal cord injury: a randomized controlled trial. Rehabil Psychol 2009; 54: 1-15.

105 Kahan JS, Mitchell JM, Kemp BJ, Adkins RH. The results of a 6-month treatment for depression on symptoms, life satisfaction, and community activities among individuals aging with a disability. Rehabil Psychol 2006; 51: 13-22.

106 Craig AR, Hancock K, Dickson H, Chang E. Long-term psychological outcomes in spinal cord injured persons: results of a controlled trial using cognitive behavior therapy. Arch Phys Med Rehabil 1997; 78: 33-38.

107 Elliot TR, Berry JW. Brief problem-solving training for family caregivers of persons with recent-onset spinal cord injuries: a randomized controlled trial. J Clin Psychol 2009; 65: 406-422. 